\title{
Um Olhar de Alunos da EJA sobre Impactos Ambientais do Turismo Costeiro em Ajuruteua (Bragança-PA)
}

\author{
Orildo Ribeiro dos Santos ${ }^{1}$
}

\begin{abstract}
Resumo:
Neste artigo, apresentam-se as investigações sobre as concepções apontadas pelos alunos da EJA sobre os impactos ambientais e sociais presentes nas vilas do entorno da praia de Ajuruteua. Os dados foram levantados por meio de perguntas diretas e indiretas. As informações investigadas foram analisadas, considerando a teoria sobre meio ambiente segundo Sauvé. 0 público-alvo foram alunos da 1aㅡ etapa e 2ª etapa do Ensino Fundamental da Educação de Jovens e Adultos (EJA) residentes nas localidades: Vila do Bonifácio, Vila do Meio e Vila Velha ou Vila dos Pescadores. São alunos praianos, que residem próximos da praia de Ajuruteua, localizada na região do Nordeste paraense, na cidade de Bragança-PA. Os alunos demonstram preocupação com o meio ambiente, e mesmo com um precário conhecimento teórico sobre 0 assunto, amparados pelas orientações da escola, fazem 0 possível para minimizar os impactos deixados pelos veranistas. Mediante a pesquisa os alunos foram indagados sobre vários temas a respeito da cultura, comércio, saneamento básico, número de moradores, influência dos veranistas sobre a cultura local. Conclui-se que a educação ambiental deveria ser uma disciplina obrigatória para todos os níveis de ensino e não apenas um tema transversal.
\end{abstract}

Palavras-chave: Educação de Jovens e Adultos (EJA). Impactos ambientais. Ajuruteua.

\section{YOUNG AND ADULT STUDENTS LOOK ABOUT ENVIRONMENTAL IMPACTS OF COASTAL TOURISM AT AJURUTEUA (BRAGANÇA-PA, BRASIL)}

\begin{abstract}
:
This article investigated the conceptions outlined by the students of the EJA on the environmental and social impacts present in the surrounding villages Beach Ajuruteua. The data were collected through direct and indirect questions and handled according to descriptive statistics. The data collected were analyzed considering the theory of environment according
\end{abstract}

1 Mestrando na Universidade Federal do Pará e aluno da Especialização de Educação de Jovens e Adultos na mesma instituição. Graduado em Biologia pela UFPA e em Química pelo Instituto Federal do Pará http://lattes.cnpq.br/2655764068413155. orildo.santos@gmail.com 
to Sauvé. The target audience were students of the 1aㅡㄹ $2^{\underline{a}}$ etapa of primary education of adult education, students residing in the villages to the surroundings Beach Ajuruteua, located in Para Northeast in the city of Bragança-PA. Students demonstrate concern for the environment, even with little theoretical knowledge on the subject, but the lack of knowledge of laws and school orientation, do the minimum to minimize the impacts left by vacationers. Students were asked about various topics concerning the culture, trade, sanitation, number of residents, vacationers influence on local culture. Environmental education should be a compulsory subject for all levels of education and not just a cross-cutting theme for teaching.

Keywords: Education for young adults. Environmental impacts. Ajuruteua. 
No presente trabalho propõe-se retratar concepções trazidas pelos alunos da Educação de Jovens e Adultos (EJA) sobre os impactos ambientais que ocorrem nas vilas do entorno da praia de Ajuruteua, situada a $36 \mathrm{~km}$ do município de Bragança, no Pará. Neste artigo verifica-se que os alunos apontam para alguns impactos ambientais e sociais deixados pelos veranistas na praia e em suas proximidades, estando pautado na pesquisa qualitativa com apoio estatístico, buscando de forma detalhada maior compreensão sobre as percepções. Para Richardson (1999), o estudo qualitativo pode ser descrito pela tentativa de uma compreensão mais complexa do assunto, pois caracteriza bem as situações apresentadas pelos entrevistados. Os dados foram coletados por meio de perguntas diretas e indiretas aos alunos da $1^{\mathrm{a}}$ e $2^{\mathrm{a}}$ etapas da EJA, com intuito de que apontassem, segundo suas concepções, os impactos causados nos campos físico e social da localidade. Os dados foram analisados segundo a estatística descritiva com o auxílio da ferramenta Excel 2013, considerando algumas categorias de análise segundo Sauvé, entre outros autores.

\section{A importância do turismo em áreas costeiras}

Teoricamente, a atividade turística é importante para qualquer economia, seja ela nacional, regional ou local. A importância do turismo em áreas costeiras manifesta-se por meio dos pequenos empregos gerados pelas empresas de hotelaria para os residentes locais. Os pescadores tiram seu sustento com a venda do pescado a turistas e restaurantes. Outra importância do turismo está na melhoria da infraestrutura para receber os visitantes, consequentemente beneficiando os moradores. O deslocamento constante das pessoas à praia aumenta o consumo, motiva a diversidade de produção de bens e serviços e possibilita a geração de lucro, contribuindo para emprego e renda.

\section{Definição de Impacto Ambiental}

Segundo o Artigo $1^{\circ}$ da Resolução $n^{\circ}$ 001/86 do Conselho Nacional do Meio Ambiente (Conama), Impacto Ambiental é 
qualquer alteração das propriedades físicas, químicas, biológicas do meio ambiente, causada por qualquer forma de matéria ou energia resultante das atividades humanas que afetem diretamente ou indiretamente: a saúde, a segurança, e o bem-estar da população; as atividades sociais e econômicas; a biota; as condições estéticas e sanitárias ambientais; a qualidade dos recursos ambientais.

O Impacto Ambiental está associado à alteração ou efeito ambiental considerado significativo por meio da avaliação do projeto de um determinado empreendimento, podendo ser negativo ou positivo (BITAR; ORTEGA, 1998).

\section{Impactos Positivos e Negativos do Turismo}

A zona costeira brasileira abriga atividades portuárias, industriais e turísticas, além da grande urbanização e da exploração turística em larga escala. Mesmo com toda a diversidade e conflitos, a zona costeira sofre uma grande valorização nos dias atuais, atraindo o interesse de inúmeros empresários e turistas. Essas diversas ações vêm ocasionado grandes prejuízos à natureza local, visto que essas atividades de construções, ocupações irregulares e todos os tipos de lixos deixados pelos visitantes estão a proporcionar contaminação do solo, das águas e das áreas costeiras.

Essas atividades podem ser positivas ou negativas: as positivas trazem benefícios para as comunidades receptoras e negativas quando causam estragos à localidade e sua população. Certos aspectos podem ser apontados em relação a alguns impactos positivos do turismo, tais como geração de empregos e favorecimento das artes e do artesanato. Por outro lado, os negativos, provenientes do aumento de carros no trânsito e elevação nos preços dos produtos, além de tensões percebidas pelos residentes.

\section{Caracterizando Ajuruteua e seu Entorno}

A praia de Ajuruteua tem cerca de 2,5 km de extensão, constituindo-se em uma ponta de terra entre manguezais e a bacia oceânica do Atlântico localizada na faixa costeira do município de Bragança, na região Nordeste do Estado 
do Pará. Essa estreita faixa de praia desempenha importante papel na proteção da zona costeira, protegendo das forças das ondas. Na busca de um perfil de equilíbrio, este ambiente pode se alterar, após uma sequência temporal regular e previsível da natureza (ALVES, 2001).

\section{Concepções Sobre Ambiente Para Sauvé (1997)}

Sauvé (1997) divide as concepções ambientais em seis. A primeira define o ambiente como a natureza, colocando-a como algo puro, intocável, um objeto que deve ser admirado, respeitado e preservado. A segunda traz a concepção ambiental como um recurso, sendo coletiva deixada pela biofísica que sustenta a qualidade de nossas vidas. A terceira concepção apresenta o ambiente como problema, pois está sendo ameaçado pela poluição e pela degradação causadas pelos seres humanos. A quarta concepção conceitua o meio ambiente como um ambiente para se viver, no dia a dia, nas escolas, nas casas, no trabalho e no lazer, sendo caracterizados como base nos aspectos socioculturais, tecnológicos e históricos do ser humano. A quinta apresenta o ambiente como biosfera. Essa concepção fundamenta-se no ambiente como objeto de uma consciência planetária e a sexta é o ambiente como interação comunitária, buscando envolver o ambiente e a coletividade humana. Observa-se que as seis concepções interagem socialmente com o ambiente, o ser humano, mas apresentando as suas particularidades individuais.

\section{Impactos Ambientais em Zonas Costeiras}

As zonas costeiras constituem-se de aproximadamente $20 \%$ de área superficial proveniente das terras emersas do planeta, apresentando-se como espaços de transição entre os ecossistemas terrestres e os ecossistemas marinhos. São compostas por dois elementos integrados ou sistemas principais: o Sistema Natural (físico e biológico) e o Sistema Socioeconômico. Cada um deles apre- 
senta uma dinâmica própria e certa vulnerabilidade, as quais estão associadas às suas interações, de forma que um pode alterar ou condicionar a dinâmica do outro (PEREIRA, 2001).

Os impactos ambientais em zonas costeiras são, de certa forma, naturais, porque estão relacionados à dinâmica dos sistemas naturais, cujas transformações podem ou não ser induzidas pelo homem. Pode-se dizer que, também, são riscos sociais por estarem relacionados aos processos sociais decorrentes da ocupação desordenada do espaço, resultando em carências sociais e em baixos níveis de desenvolvimento humano (EGLER, 1996).

Partindo do princípio da relação humana, ambientes naturais costeiros e suas possíveis degradações ao longo do tempo, causadas pela dinâmica e ocupação desordenada das pessoas na área litorânea, é importante observar e analisar as três classificações trazidas por Afonso (1999).

Afonso (1999) classifica os impactos ambientais em zonas costeiras em três categorias:

(1) Impactos por perda de recursos, os quais podem ocorrer devido à contaminação por resíduos sólidos e/ou líquidos das águas superficiais, subterrâneas e do solo, dos manguezais, contaminação do ar, desmatamento, sobre-exploração de recursos pesqueiros e extração mineral.

(2) Impactos por conflito do uso do solo entre áreas industriais e urbanas, áreas portuárias/industriais e turísticas, áreas urbanas/industriais, áreas de pesca, áreas portuárias e de conservação, e

(3) Impactos nas áreas costeiras por riscos de acidentes, os quais incluem acidentes em áreas industriais e portuárias, no transporte de produtos perigosos, erosão e deslizamento nas praias e encostas serranas.

Esses três aspectos apontados pelo autor apresentam reflexos diretamente nas estruturas sociais, políticas, econômicas e populacionais, com todos esses processos sendo feitos no suporte do ambiente natural. O ambiente não é apenas um componente a ser degradado, mas uma base que possibilita a vida (LUTZ; PRSKAWETZ; SANDERSON, 2002). 
Sabe-se que a constituição da demografia enquanto área particular das ciências, a qual busca envolver a interdisciplinaridade, interação entre a população e o ambiente, vem aparecendo como uma questão ora simplista, ora complexa, apresentando-se de modo simplista quando a pressão populacional aumenta sobre o ambiente e ocorre de modo complexo quando investiga e analisa os elementos dessa relação (MCNEILL; KREUTER; SUBRAMANIAN, 2006).Em meio às opiniões, busca-se mostrar que as relações entre população e ambiente, especificamente no caso da zona costeira de Ajuruteua/PA, são bem complexas, significando que o crescimento populacional ainda existe. Esse crescimento populacional pode ser visto como um problema em si, uma vez que os manguezais estão sendo degradados aos poucos.

Pelos relatos dos alunos, a dinâmica da população envolve mais do que o seu crescimento por apresentar uma problemática da educação ambiental, a qual estabelece um tema muito propício para discussão e reflexão em torno do impacto das práticas de resistência e de expressão das demandas da população nas áreas mais afetadas pelos crescentes impactos ambientais.

Para entender essa dinâmica é necessário compreender as especificidades da produção dos espaços nos quais as populações vivem, realçando a dialética dessa relação, que deve ser entendida, também, por meio de trabalhos conceituais que tragam elementos para entender as consequências dessa dinâmica. Pela educação ambiental é possível modificar um quadro de crescente degradação socioambiental, mas apenas essas medidas são incipientes para o contexto socioambiental (JACOBI et al., 2003).

\section{Leitura do Ambiente \& Leitura de Mundo}

A Educação de Jovens e Adultos é um palco de teorias, práticas e reflexões que transbordam os limites da escolarização em sentido rigoroso, visto que envolve processos formativos distintos, em que podem ser incluídas iniciativas visando à qualificação profissional do indivíduo, à formação política e inúmeras questões culturais pautadas em outros espaços que não o escolar. Além disso, 
mesmo quando se focalizam os processos de escolarização de jovens e adultos, os cânones da escola regular, com seus tempos e espaços rigidamente delimitados, imediatamente apresentam-se como problemáticos (DI PIERRO, 2001).

A escolarização de jovens e adultos informada pelo paradigma da educação popular dialogou criticamente com essa tradição porque se referiu, sobretudo, ao universo cultural dos educandos e questionou a valorização diferencial do conhecimento científico diante dos saberes construídos nas práticas de trabalho e convivência no meio popular. O momento atual é caracterizado por inúmeras transformações no que se refere às relações sociais, o que conduz à formação de grupos e organizações, levando assim a novas formas de comportamento social (CUNHA, 2010).

Atualmente os problemas ambientais vêm sendo discutidos nos espaços formais, informais e não formais da educação, fazendo com que alguns educadores levem o assunto para dentro das salas de aula. A necessidade da inclusão da educação ambiental na EJA, portanto, serve como meio para sensibilizar os indivíduos sobre as ações que inferem na sua própria existência, visto que contribui para a formação do cidadão. Além disso, a educação ambiental é ressaltada pela Constituição Brasileira, sendo necessária sua inserção em todos os níveis de ensino.

Influenciado pela teoria de Paulo Freire, entendo que a educação ambiental é uma educação problematizadora, visto que se desenvolve com várias possibilidades de reflexões à procura de alternativas que se entrelacem com o modelo de educação tradicional. Esse modelo tradicional de educação atuante trabalha em cima de um modelo que prefere transmitir o conhecimento ao invés de construir com os educandos. Paulo Freire problematiza a construção do conhecimento teórico envolvendo a prática dos alunos, fazendo com que elaborem suas próprias concepções de conhecimento.

Para Paulo Freire (2003), “[...] o educador já não é o que apenas educa, mas o que, enquanto educa é educado, em diálogo com o educando que, ao ser educado, também educa. Ambos, assim, se tornam sujeitos do processo em que crescem juntos [...]” (p. 68). 
E ainda:

Quanto mais se problematizam os educandos, como seres no mundo e com o mundo, tanto mais se sentirão desafiados. Tão mais desafiados, quanto mais obrigados a responder ao desafio. Desafiados, compreendem o desafio na própria ação de captá-lo. Mas, precisamente porque captam o desafio como um problema em suas conexões com outros, num plano de totalidade e não como algo petrificado, a compreensão resultante tende a tornar-se crescentemente crítica, por isto, cada vez mais desalienada (FREIRE, 2003, p. 70).

Os conceitos de educação ambiental foram efetuados a partir do final dos anos $80^{2}$ com o termo alfabetização ecológica. Sauvé (1997) traz a classificação de educação ambiental partindo da ideia de que a educação está entrelaçada na relação humano e ambiente, podendo existir em três vertentes por meio das práticas pedagógicas, tais como: perspectiva ambiental, perspectiva educativa e perspectiva pedagógica. Essa educação é uma forma abrangente de educação que se propõe a atingir todos os cidadãos, mediante um processo pedagógico participativo permanente, o qual procura instigar no educando uma consciência crítica sobre a problemática ambiental, compreendendo-se como crítica a capacidade de captar a gênese e a evolução dos problemas ambientais (CUNHA, 2010).

\section{Resultados e Discussão}

\section{Descrição dos problemas nas vilas de Ajuruteua}

A área de Ajuruteua divide-se em três vilas. A primeira é denominada como Vila do Bonifácio, a segunda como Vila Velha ou conhecida como Vila dos Pescadores, e a terceira como Vila do Meio ou praia de Ajuruteua. Na Vila Velha residem 96 famílias, na Vila do Bonifácio 274 e na Vila do Meio 192.

${ }^{2}$ Inserido no currículo escolar, pois sabe-se que a Constituição Federal é 1988 e a LDB é de 1996. 
A Vila do Bonifácio é maior que as demais, sendo comtemplada com um posto de saúde, uma escola e duas igrejas - católica e evangélica. A fonte rentável se dá por meio da pesca artesanal e semi-industrial. Apesar de existirem pequenos comércios, a maior renda familiar é proveniente da pescaria, do programa social Bolsa Família e coleta de caranguejos.

Vila Velha foi a primeira a surgir, no entanto, com o avanço da maré ao longo do tempo, ela está se aproximando cada vez mais dos manguezais, perdendo território a cada ano, obrigando a população a migrar para a Vila do Bonifácio. Ambas as vilas apresentam como maior atividade econômica a pesca artesanal e semi-industrial. A Vila do Meio é popularmente conhecida como praia de Ajuruteua. Situada à margem do oceano Atlântico, apresenta grande número de casas e poucos moradores. A maioria das casas pertence aos veranistas que, durante as altas temporadas de veraneio, fazem-se presentes na praia. A principal economia dessa região ocorre por meio do comércio devido ao grande número de veranistas que a praia recebe em diferentes épocas do ano, com a maior concentração dando-se nos meses de julho e dezembro.

As três vilas apresentam alguns aspectos distintos porém têm em comum o impacto ambiental. A Vila do Bonifácio está perdendo território para as novas famílias que migram de outras vilas, mas muitas dessas famílias apresentam dificuldades financeiras e não possuem condições de comprar terras ou migrar para a cidade. Sendo assim, ocupam parte dos manguezais e, dessa forma, contribuem para o aumento do desmatamento, pois, além de ocuparem uma parte da área verde, extraem madeira para a construção das suas residências. Alguns moradores cortam árvores nativas para fabricação de carvão vegetal, que auxilia em sua renda.

A Vila Velha contribui para os impactos ambientais por meio da derrubada de árvores nativas para construção de currais e casas, além de receber lixo, proveniente de outras regiões, ocasionado pela maré alta, principalmente plásticos e garrafas pet. A Vila de Ajuruteua contribui bastante para os impactos ambientais. Por receber um grande número de turistas, os empresários constroem hotéis e pousadas às margens da praia, ocasionando, assim, erosão. (ver a Figura 1 a, b). 
Além dos diferentes tipos de resíduos produzidos pelos veranistas e seus animais, um problema ambiental gravíssimo é a perfuração dos poços artesianos. Esses poços são abandonados à medida que o mar avança em direção ao manguezal e, com o passar do tempo, ocorre a inundação devido à maré alta, comprometendo o lençol freático dessa área. Observam-se os poços abandonados na Figura 2 c, d.

Figura 1 - Erosão causada pelas construções
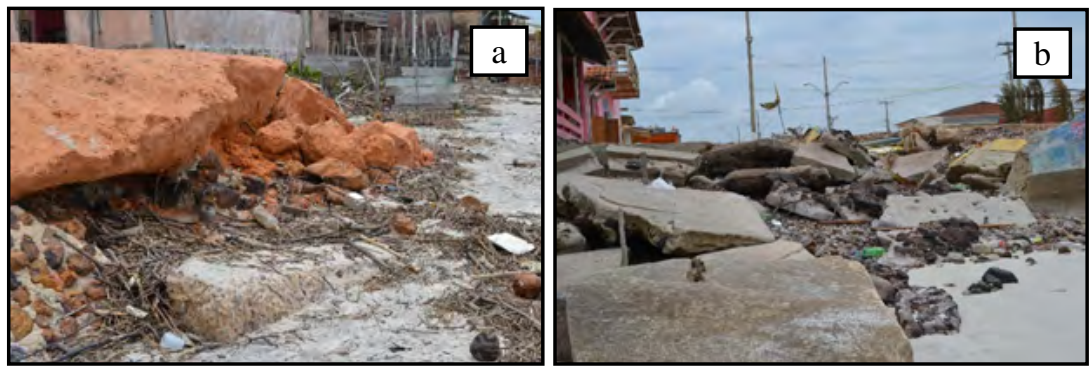

Fonte: $\mathrm{O}$ autor.

Figura 2 - Poços artesianos abandonados
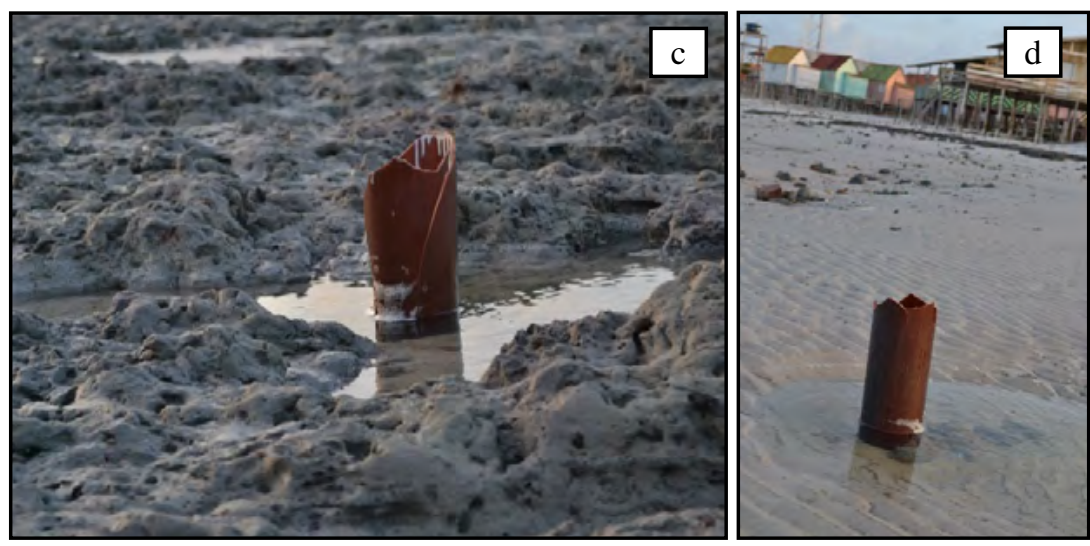

Fonte: $\mathrm{O}$ autor. 


\section{Perfil da Escola Domingos de Souza Melo}

A Escola Municipal de Ensino Fundamental Domingos de Souza Melo apresenta a seguinte estrutura: Pré-escola; Educação Infantil; $1^{\mathrm{a}}$ e $2^{\mathrm{a}}$ etapas de Ensino fundamental e Ensino Fundamental normal.

O ensino da EJA ocorre somente no período noturno, tanto para $1^{\mathrm{a}}$ etapa quanto para $2^{\text {a }}$ etapa.

Figura 3 - Vista frontal e lateral da Escola

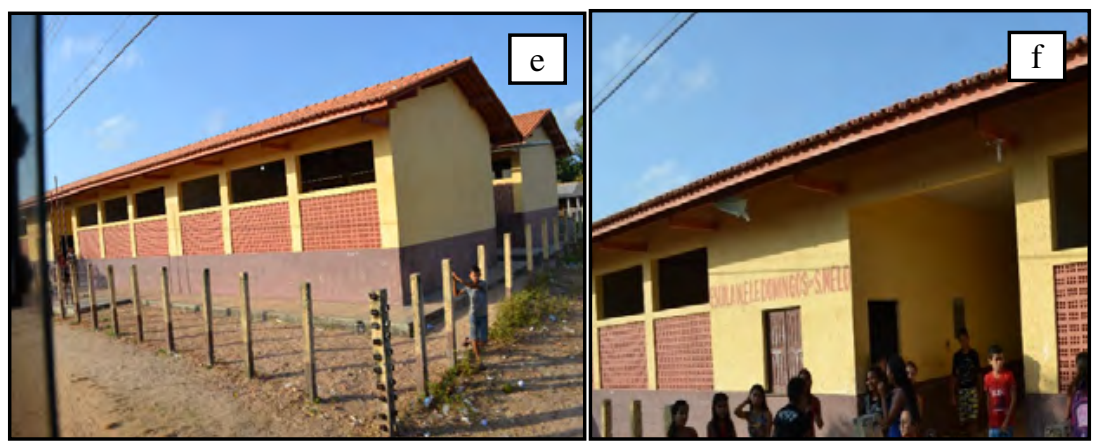

Fonte: $\mathrm{O}$ autor.

\section{Perfil dos Entrevistados}

Foram entrevistadas duas turmas de Educação de Jovens e Adultos (EJA), das quais podem ser traçados perfis como de alunos de idade avançada. A Figura 4 mostra parte desses alunos, estando eles na companhia de alguns parentes (filhos, netos e bisnetos) que os acompanham na escola e ficam até o final das aulas. Alguns vão exclusivamente para lanchar e outros para fazer companhia no retorno para casa, uma vez que nem todos moram próximo da escola. Quando foram questionados do porquê de seus estudos estarem atrasados, alguns atribuíram o fato à falta de oportunidade e outros à falta de tempo, pois tiveram filhos cedo e não houve possibilidade de frequentar as aulas e cuidar das crianças. Para algumas mulheres, no entanto, era mais difícil, pois os maridos não as deixavam frequentar as aulas. Entre os 20 entrevistados $93,25 \%$ perten- 
cem ao gênero feminino e 6,25\% ao masculino. Essas turmas apresentam uma faixa etária entre 43 e 53 anos para o gênero feminino e 42 anos para o gênero masculino. Esses $6,25 \%$ buscam avançar nos estudos. É importante ressaltar que um aluno da $2^{\mathrm{a}}$ etapa passa por algumas dificuldades em permanecer na escola, pois por ser o único homem sofre forte preconceito da comunidade local.

\section{Figura 4 - Alunos da EJA}

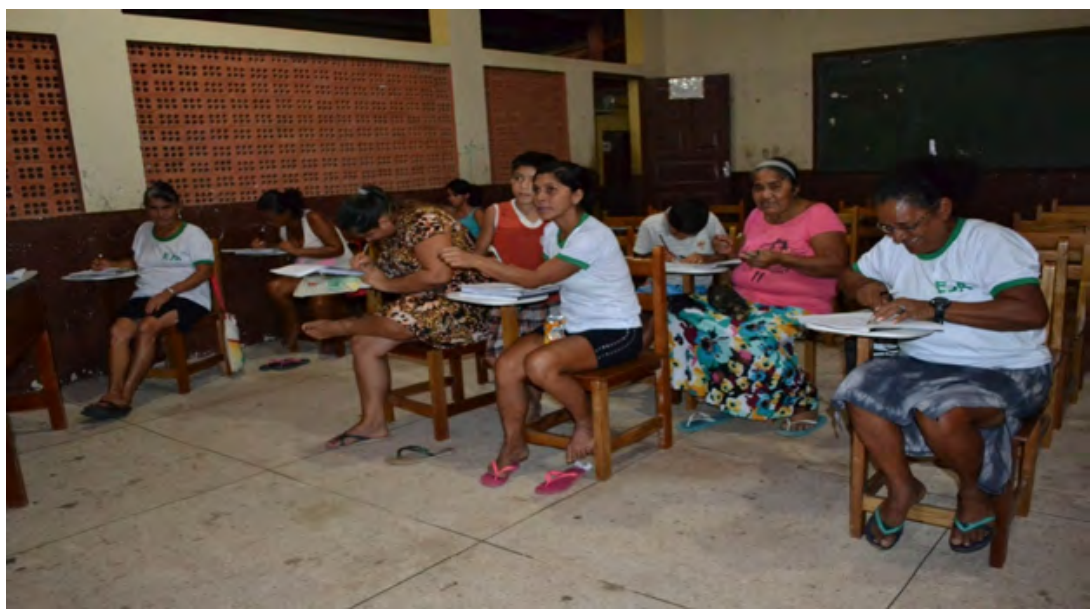

Fonte: $\mathrm{O}$ autor.

Do questionamento sobre o número de filhos, tempo de moradia e número de pessoas que habitam na mesma casa, obteve-se os seguintes resultados.

Tabela 1 - Construção familiar

\begin{tabular}{|llll|}
\hline Alunos (as) & Filhos & Tempo de moradia & $\begin{array}{l}N^{o} \text { de pessoas } \\
\text { por casa }\end{array}$ \\
\hline $1^{\circ} \mathrm{EJA}$ & 4,12 & 16,25 & 4,37 \\
\hline $2^{\circ} \mathrm{EJA}$ & 4,87 & 18,25 & 4,62 \\
\hline
\end{tabular}

Fonte: Dados da Pesquisa.

A Tabela 1 mostra que há pouca diferença no que diz respeito à média em termos de número de filhos, tempo de moradia e números de pessoas por casa. 
Os alunos foram questionados nos seguintes aspectos: materiais usados para construção de suas moradias; origem do abastecimento de água; destino do lixo dados por eles e o tipo de fossa sanitária que utilizavam. Essas perguntas tiveram como intuito averiguar o saneamento básico (ver Figuras 2, 3, 4 e 5), já apresentadas anteriormente.

Tabela 2 - Saneamento básico/ tipo de material ultilizado na construção das casas

\begin{tabular}{|l|l|l|}
\hline $\begin{array}{l}\text { Tipo de Material de } \\
\text { Construção }\end{array}$ & $1^{a}$ EJA & $2{ }^{a}$ EJA \\
\hline Alvenaria & $50 \%$ & $50 \%$ \\
\hline Madeira & $25 \%$ & $50 \%$ \\
\hline Outros & $25 \%$ & \\
\hline
\end{tabular}

Fonte: Dados da Pesquisa.

Os resultados da Tabela 2 mostram que ainda existem algumas famílias que vivem na linha abaixo da pobreza, pois $25 \%$ da $1^{\mathrm{a}}$ etapa da EJA são de pessoas que não apresentam renda fixa, não possuem condições para construírem casas mais confortáveis e são obrigadas a viver em moradias improvisadas, cercadas por telhas, plásticos e varas de manguezais, entre outros

Comparando a situação de moradias entre a $1^{\mathrm{a}}$ e a $2^{\mathrm{a}}$ etapa, observa-se que $50 \%$ delas apresentam casas construídas com materiais de alvenaria, mas $25 \%$ da $1^{\mathrm{a}}$ etapa e $50 \%$ da $2^{\mathrm{a}}$ etapa apresentam casas construídas em madeira. Outros $25 \%$ da $1^{a}$ etapa têm casas construídas com varas extraídas dos manguezais e algumas delas cercadas com telhas de Brasilit.

No que se refere ao saneamento básico, veremos a tabela 3:

Tabela 3 - Saneamento básico/destino do lixo

\begin{tabular}{|l|l|l|}
\hline Destino do Lixo & $1^{a}$ EJA & $2{ }^{a}$ EJA \\
\hline Queimado & $50 \%$ & $62,50 \%$ \\
\hline Coletado & $50 \%$ & $37,50 \%$ \\
\hline
\end{tabular}

Fonte: Dados da Pesquisa. 
Segundo alguns relatos, incluindo os dos alunos, o carro do lixo nem sempre passa para a coleta e, devido à demora, os resíduos se acumulam nos quintais. Por isso, os moradores preferem queimar, ao invés de aguardar o carro coletor. Segundo os moradores, queimando o lixo não há amontoamento, assim não atrai roedores e pequenos insetos.

Tabela 4 - Saneamento básico/tipo de fossa

\begin{tabular}{|l|l|l|}
\hline Tipo de Fossa & $1^{\mathrm{a}} \mathrm{EJA}$ & $2^{\mathrm{a}} \mathrm{EJA}$ \\
\hline Fossa & $50 \%$ & $75 \%$ \\
\hline Outros & $50 \%$ & $25 \%$ \\
\hline
\end{tabular}

Fonte: Dados da Pesquisa.

O tipo de fossa também retrata o saneamento básico das comunidades, vilas e cidades. É possível verificar, conforme a Tabela 4, que 50\% dos alunos da $1^{\mathrm{a}}$ etapa e $75 \%$ da $2^{\mathrm{a}}$ etapa da EJA usam fossa; os outros $50 \%$ da $1^{\mathrm{a}}$ etapa e $25 \%$ da $2^{\text {a }}$ etapa utilizam outros destinos. Geralmente este outro destino é uma pequena casa coberta localizada no fundo dos quintais, onde existe um buraco com, aproximadamente, um metro de profundidade para depositarem seus resíduos fecais. O grande problema está em depositarem os dejetos biológicos diretamente no solo, contaminando o ambiente e o lençol freático.

\section{Percepção dos Impactos Ambientais para Alunos da EJA}

Afinal, o que é impacto socioambiental? Pode-se dizer que é a reação da sociedade ou do meio ambiente a uma ação humana. Partindo deste princípio pode-se avaliar os seguintes impactos apontados pelos alunos da $1^{\mathrm{a}}$ e $2^{\mathrm{a}}$ etapas da EJA.

Foram feitos aos alunos os seguintes questionamentos: a) existe órgão fiscalizador?; b) há participação da comunidade na gestão das áreas protegidas?; c) as áreas protegidas têm sofrido algum tipo de pressão?; d) existe coleta seletiva?; e) quais os principais tipos de lixo que aparecem mais frequentemente? 
Por meio desses questionamentos pode-se observar as seguintes respostas em termos do órgão fiscalizador. $100 \%$ da $1^{a}$ etapa disseram que existe órgão fiscalizador, $12,5 \%$ da $2^{\mathrm{a}}$ etapa afirmaram que não existem órgãos ficalizadores nas reservas extrativistas. Quando questionados se há participação da comunidade na gestão das áreas protegidas, $87,5 \%$ da $1^{\text {a }}$ etapa dizem participar e $62,5 \%$ da $2^{a}$ etapa afirmaram não participar, por ser algo "chato".

Com relação às áreas protegidas e suas possíveis pressões, $100 \%$ dos alunos da $1^{\mathrm{a}}$ etapa afirmam que essas áreas passam, frequentemente, por pressões devido ao desmatamento e ocupação do espaço próximo aos manguezais, no entanto $12,5 \%$ dos alunos da $2^{\mathrm{a}}$ etapa disseram não; em outras palavras, as áreas protegidas não passam por nenhum tipo de pressão.

Referindo-se à coleta seletiva do lixo, $75 \%$ da $1^{\mathrm{a}}$ etapa e $100 \%$ da $2^{\mathrm{a}}$ etapa disseram não existir esse tipo de coleta, mesmo os professores tendo comentado em sala de aula sobre o referido assunto. Segundo os entrevistados, há dificuldades na hora de selecionar o lixo e decartá-lo.

Quando foram perguntados sobre quais os principais tipos de lixo que aparecem mais frequentemente, a $1^{\mathrm{a}}$ etapa afirma ser: plástico (87,5\%), papel (25\%), vidro (62,5\%); a $2{ }^{\text {a }}$ etapa diz ser: plástico $(87,5 \%)$, papel $(25 \%)$, latas $(6 \%)$ e vidros $(4 \%)$.

Nesse contexto pode-se relacionar com algumas das seis concepções destacadas por Sauvé (1997), tais como: a segunda, apontando o ambiente como um recurso de qualidade de vida; terceira, o ambiente como um problema, pois a poluição e a degradação causadas pelo ser humano ameaçam o meio ambiente, embora a educação ambiental e outras ações venham limitar algumas ações antrópicas. Para Faggionato (2005), a percepção ambiental pode ser definida como uma tomada de consciência das problemáticas ligadas ao ambiente, ou seja, o ato de perceber o ambiente em que se está inserido, aprendendo a proteger e cuidar. Os dados nos mostram que os alunos da $1^{\text {a }}$ etapa da EJA apresentam maior preocupação com o meio ambiente, mesmo sem ter um pleno conhecimento teórico sobre este, apesar de algumas atitudes cometidas não serem 
corretas Vale ressaltar que as atitudes prejudiciais ao meio ambiente não são intencionais, mas, por serem obrigados, devido às condições financeiras, são conduzidos para tal ato.

\section{Aspectos Sociais da Comunidade Segundo a Visão dos Alunos da EJA}

As seguintes perguntas foram feitas aos alunos: Existe preocupação com a educação ambiental? Existe alguma ação para acolhimento e orientação do turismo? O que a comunidade precisa?

Na primeira pergunta $100 \%$ da $1^{a}$ etapa afirmam sim, no entanto $62,5 \%$ da $2^{\mathrm{a}}$ etapa disseram não existir preocupação por parte dos moradores, visto que muitos jogam lixo pelas ruas, extraem árvores da mata nativa. Na segunda pergunta os alunos da $1^{a}$ etapa responderam sim, enquanto os da $2^{a}$ etapa disseram não, argumentando não haver orientação sobre como lidar com os turistas.

Quanto ao quesito "o que falta à comunidade?", ambas gostariam de ter água potável, pois essa é uma das grandes necessidades das comunidades locais, devido ao fato de o lençol freático estar contaminado com a água salgada do mar. As demais necessidades se dividiram em $75 \%$ asfalto, $62,5 \%$ policiamento e $75 \%$ muro da escola para $1^{\mathrm{a}}$ etapa. Para a $2^{\mathrm{a}}$ etapa: $25 \%$ policiamento e $12,5 \%$ farmácia entre outros.

Analisando as respostas, conclui-se que os alunos demostram uma preocupação com o meio ambiente, mas é incipiente ainda. Apesar de alguns saberem o que é impacto ambiental, não têm atitudes nem forças para combater, o que revela a falta de conhecimento teórico do assunto e de informações necessárias juntos com as autoridades competentes, precisando de mais orientações em relações às leis ambientais.

Neste contexto pode-se analisar a sexta concepção trazida por Sauvé (1997), em que o ambiente engloba a coletividade humana, envolvendo a necessidade da democracia e da participação na relação da comunidade com o meio ambiente. 


\section{Impactos do Turismo para Residentes}

O turismo apresenta efeitos econômicos, sociais, culturais e ambientais múltiplos e produz resultados. Sendo, porém, uma atividade capitalista como outra qualquer, torna-se contraditória, ou seja, gera benefícios e simultaneamente problemas e conflitos. Neste contexto, buscamos saber a opinião dos alunos residentes em destinos turísticos, pois a população local é parte essencial para o bom desenvolvimento do turismo.

Para avaliar os impactos e benefícios deixados pelos turistas, foram feitas as seguintes perguntas aos alunos, como se observa na Tabela 5.

Tabela 5 - Impactos do turismo para residentes

\begin{tabular}{|lll|}
\hline Perguntas diretas & $1^{a} E J A$ & $2^{a} E J A$ \\
\hline Polui o espaço? & $75 \%$ & $87,5 \%$ \\
\hline Animais na praia? & $50 \%$ & $12,5 \%$ \\
\hline $\begin{array}{l}\text { Não demonstram respeito pelos } \\
\text { moradores? }\end{array}$ & $25 \%$ & 0 \\
\hline
\end{tabular}

Fonte: Dados da Pesquisa.

Ambas as turmas da EJA, com $75 \%$ e $87,5 \%$, afirmaram que os turistas poluem o espaço das praias e os locais nos quais se hospedam. Além disso, alguns alunos justificam a poluição dizendo que os turistas poluem porque não têm concepção de educação ambiental, enquanto outros agem assim por não haver lixeiras suficientes na praia e nas vilas.

Não somente o lixo, mas animais também são comuns na praia. Alguns são de vilas do entorno que buscam por alimento, outros são de turistas. De certa forma esses animais contaminam a praia, o que é confirmado por ambas as turmas. Isso pode gerar problemas à saúde de moradores e veranistas, bem como de estética à praia. Vale ressaltar que somente $50 \%$ dos alunos da $1^{\mathrm{a}}$ etapa e $12,5 \%$ da $2^{\text {a }}$ etapa falaram sobre o assunto e afirmaram que os animais contaminam a praia. Diante do exposto, há necessidade de um controle de zoonoses na praia e nas vilas. 
Com relação a terceira pergunta, $25 \%$ dos alunos da $1^{a}$ etapa afirmaram que os turistas não demonstram respeito e são mal-educados com os moradores. Segundo o relato dos alunos da $2^{\mathrm{a}}$ etapa, os turistas geralmente são mal-educados e pioram quando estão sob efeito de bebida alcoólica, porém não são todos, tem muita "gente boa".

Os fatores que influenciam a mudança de comportamento dos residentes são: poluição ambiental, economia local e degradação do espaço físico. Para saber a visão dos alunos nesses quesitos foram realizadas as seguintes perguntas (ver Tabela 6).

Tabela 6 - Visão sobre a economia e poluição

\begin{tabular}{|lll|}
\hline Perguntas & $1^{a}$ Etapa & $2^{a}$ Etapa \\
\hline Poluição ambiental & $12,5 \%$ & $87,5 \%$ \\
\hline Economia Local & $75 \%$ & $75 \%$ \\
\hline Degradação do espaço físico & $37,5 \%$ & $12,5 \%$ \\
\hline
\end{tabular}

Fonte: Dados da pesquisa.

Segundos $12,5 \%$ dos alunos da $1^{\mathrm{a}}$ etapa, há poluição ambiental na localidade, mas não é tão expressiva, no entanto os alunos da $2^{\mathrm{a}}$ etapa, com $87,5 \%$, afirmaram que há sim grande poluição ocasionada pelo turismo, tanto na parte física da praia paia quanto na sonoridade abusiva.

No que se refere à economia local, ambas as turmas, com $75 \%$, afirmaram que o turismo é fundamental para o desenvolvendo do comércio local. Em relação à degradação do espaço físico, $37 \%$ dos alunos da $1^{\text {a }}$ etapa afirmaram que os turistas, direta e indiretamente, influenciam para aumentar a degradação do espaço físico com a construção de mais hotéis e pousadas na região; 12,5\% da $2^{\mathrm{a}}$ etapa dizem que o turismo contribui para o aumento da degradação, mas não diretamente, pois os maiores responsáveis são os empresários com as construções.

Quanto à participação do veranista na cultura local, observa-se no Gráfico 1 que mais de $70 \%$ dos alunos de ambas as turmas afirmaram que os turistas participam. 
Gráfico 1 - Cultura local e o turismo

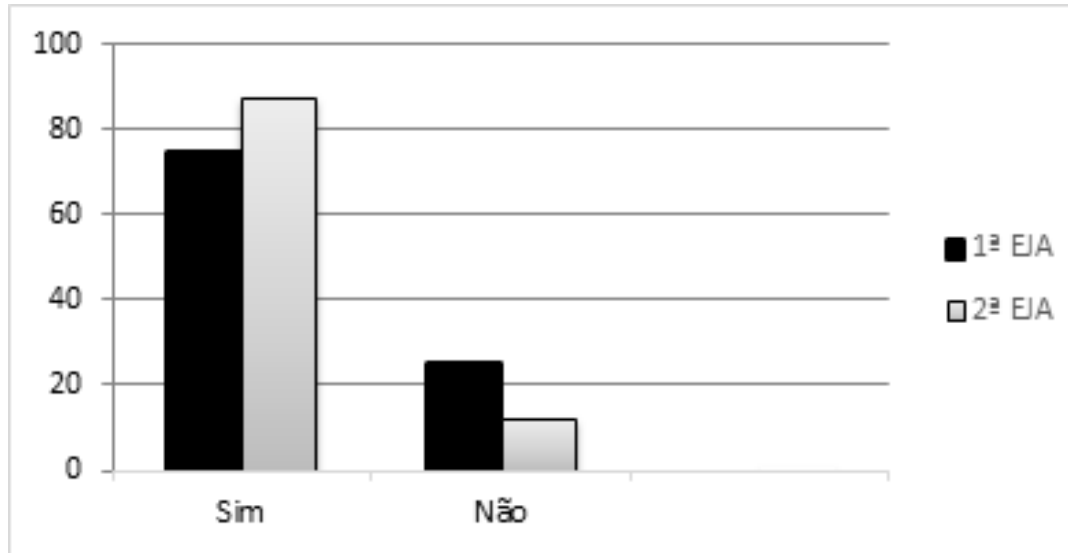

Fonte: Dados da pesquisa.

O envolvimento e a participação dos turistas, no entanto, podem causar alguns efeitos de aculturação e imitação, produzindo assim uma substituição nos gostos e hábitos da cultura da população das vilas, podendo ocasionar um fenômeno de modificação da sociologia rural e urbana por parte de quem recebe essa interação cultural.

\section{Economia Local: aspectos econômicos.}

Quando o turismo é considerado um rendimento financeiro essencial em uma escala local, contribui para o sustento das comunidades anfitriãs e para o seu desenvolvimento. É necessário, contudo, o monitoramento que advém da opinião dos moradores após os estágios iniciais do desenvolvimento. Para isso foi perguntado aos alunos da Educação de Jovens e Adultos sobre a influência da atividade econômica na localidade proveniente do turismo.

O Gráfico 2 mostra a influência do turismo na economia local, no entanto essa economia ofertada pelos turistas é dividida entre os comerciantes da localidade e aqueles que migram no período de alta temporada de veraneio para as vilas. Ver Gráfico 2. 
Gráfico 2 - Economia e turismo

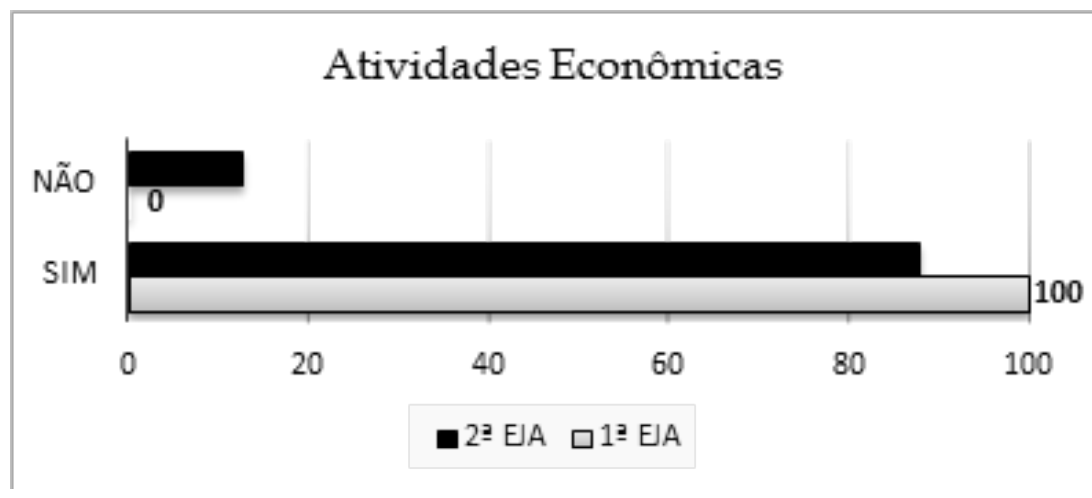

Fonte: Dados da pesquisa.

Nota-se que, segundo as turmas, os moradores das vilas aguardam pela renda advinda das épocas de veraneio, influenciando diretamente o comércio local, pois algumas mercadorias são mais caras do que em outras épocas no ano.

Gráfico 3 - Pequenos comerciantes de outras vilas

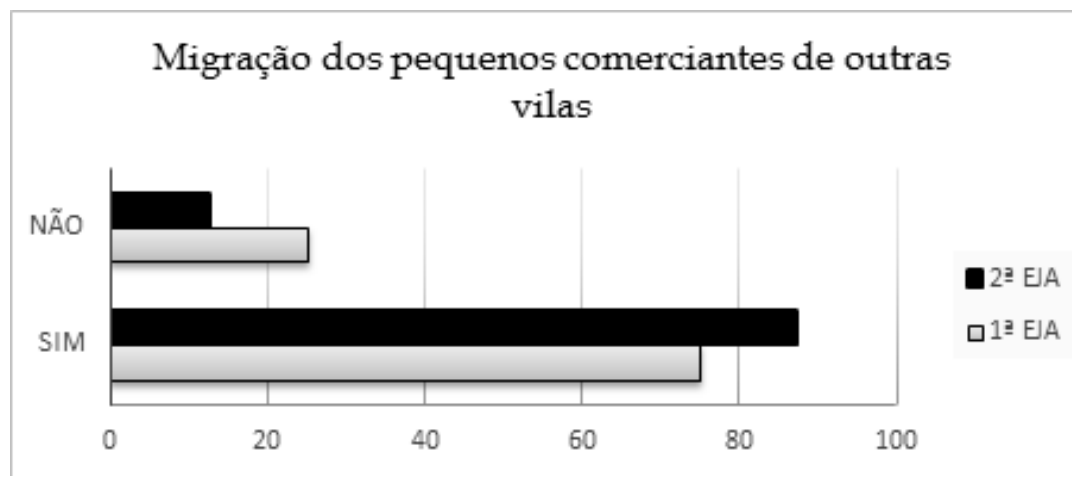

Fonte: Dados da pesquisa.

Segundo os moradores, a chegada de vendedores ambulantes no período de alta temporada, veraneio, é um problema, pois aumenta a concorrência. Essa migração é confirmada pelos alunos no Gráfico 3. Quando questionados sobre 
a migração de comerciantes para a praia, $75 \%$ da $1^{\mathrm{a}}$ etapa e $87,5 \%$ da $2^{\mathrm{a}}$ etapa confirmam que os comerciantes migrantes poluem a praia constantemente, deixando lixo espalhado por onde passam.

As principais atividades comerciais alavancadas pelo turismo no período de alta temporada são: aluguéis de casas, vendas de comidas regionais, comércio e aluguel de barcos, segundo o que foi informado pelos alunos. Ver Tabela 7.

Tabela 7 - As principais atividades que geram lucro para comunidade

\begin{tabular}{|lll|}
\hline Perguntas & $1^{\mathrm{a}}$ EJA & $2^{a}$ EJA \\
\hline Casa & $81,25 \%$ & $87,5 \%$ \\
\hline Comidas & $87,5 \%$ & $81,25 \%$ \\
\hline Comércio & $87,5 \%$ & $87,5 \%$ \\
\hline Barcos & $25 \%$ & 0 \\
\hline
\end{tabular}

Fonte: Dados da pesquisa.

Para os moradores essas atividades são formas de obter dinheiro a mais para complementar sua renda. Dado o contexto cultural e social das vilas, tornam-se importantes as informações apresentadas pelos moradores sobre os turistas, pois geram bases indispensáveis para um planejamento adequando às localidades turísticas.

\section{Considerações Finais}

Por meio do estudo levantado, conclui-se que a percepção ambiental formada nos alunos investigados é incipiente, revelando a necessidade de desenvolver uma educação ambiental mais atuante na Educação de Jovens e Adultos. Diante do exposto, é importante refletir sobre a necessidade de construção teórica e prática, nos alunos investigados e nas comunidades, procurando assim desenvolver mais fortemente a percepção ambiental, buscando alertá-los para os principais problemas apontados, tais como: a falta de água potável, erosões, doenças e desmatamento. Esses são importantes indicadores de impacto ambiental, os quais não estão sendo levados em consideração pelas autoridades, visto que há muito tempo esses problemas se repetem e a cada ano aumentam. 
Para minimizar, uma solução seria aprofundar-se nos estudos da percepção nas relações ser humano-ambiente, com o intuito de favorecer o uso mais sustentável dos recursos naturais.

A educação ambiental, nos três aspectos apontados por Afonso (1999), é fundamental para ser trabalhada em sala de aula, principalmente porque os alunos apresentaram pouco interesse em preservar o meio ambiente, derivado da falta de conhecimento sobre o assunto e pelas raras participações nos encontros promovidos pelo Instituto Chico Mendes de Conservação da Biodiversidade (ICMBIO), o qual é responsável pela fiscalização da Reserva Extrativista Marinha de Caeté Taperaçu (Resex). Sabendo que as três vilas estão situadas dentro da Resex é importante trabalhar com os alunos e moradores os três principais aspectos do ambiente costeiro: o natural, o socioeconômico e o uso do solo. Assim, teríamos a teoria na prática. Para Sauvé (1997), a educação ambiental está entrelaçada na relação humano e ambiente.

\section{Referências}

AFONSO, C. M. Uso e ocupação do solo na Zona Costeira do Estado de São Paulo: uma análise ambiental. São Paulo: Editora Anablume, 1999. 185p.

ALVES, M. A. M. S. Morfodinâmica e Sedimentologia da praia de Ajuruteua - NE do Pará. 2001. 104 p. Dissertação (Mestrado) - Universidade Federal do Pará, Centro de Geociências. Belém, 2001.

BITAR, O. Y.; ORTEGA, R. D. Gestão ambiental. In: OLIVEIRA, A. M. S.; BRITO, S. N. A. (Ed.). Geologia de engenharia. São Paulo: Associação Brasileira de Geologia de Engenharia (Abge), 1998. p. 499-508. Cap. 32.

CARVALHO, Isabel. Territorialidades em luta: uma análise dos discursos ecológicos. São Paulo: Instituto Florestal de São Paulo, 1991.

. Qual educação ambiental? Elementos para um debate sobre educação ambiental e extensão rural. Agroecologia e Desenvolvimento Rural Sustentável, 2(2):43-51, 2001.

CUNHA, Amelia Teresinha Brum da. Educação Ambiental e Educação de Jovens e Adultos: a urgência da aproximação na construção de saberes ecológicos. In: ENCONTRO DE PESQUISA EM EDUCAÇÃO DA REGIÃO SUL - ANPED SUL, 8., Formação, ética e políticas: qual pesquisa? Qual educação? 2010, Londrina. Londrina, PR: Anped, 2010. 
DI PIERRO, M. C. Visões da Educação de Jovens e Adultos no Brasil. In: Cadernos Cedes, ano XXI, n. 55, p. 57-77, nov. 2001.

EGLER, C. A. G. Potencial de risco ambiental na zona costeira. In: MORAES, A. C. R. de et al. (Org.). Macrodiagnóstico da zona costeira do Brasil na escala da União. Brasília: Ministério do Meio Ambiente e da Amazônia Legal, 1996.

FAGGiONATO, S. Percepção ambiental. [on-line] 2005. Disponível em: <http:// www.scielo.br/scielo.php?script=sci_arttext\&pid=S1414-81452008000300021\&lng= en\&nrm=iso >. Acesso em: 17 dez. 2015. http://dx.doi.org/10.1590/S141481452008000300021 .

FREIRE, Paulo. Pedagogia do oprimido. 37. ed. São Paulo: Ed. Paz e Terra, 2003.

GADOTTI, M. Caminhos da ecopedagogia. Debates socioambientais, 2(7):19-21, 1997. JACOBI, P. et al. (Org.). Educação ambiental, cidadania e sustentabilidade. Cadernos de pesquisa, São Paulo: SMA, n. 118, 2003.

LUTZ, W.; PRSKAWETZ, A.; SANDERSON, W. C. Introduction. In: LUTZ, W.; PRSKAWETZ, A.; SANDERSON, W. C. (Ed.). In: Population and Environment: methods of analysis. Population and Environment Review, a suplement to vol. 28, p. 1-21, 2002.

MCNEILL, L. H.; KREUTER, M. W.; SUBRAMANIAN, S. V. Social environment and physical activity: a review of concepts and evidence. Soc Sci Med., 63(4):1.011-1.022, aug. 2006.

PEREIRA, L. C. C. et al. Use and occupation at the Ajuruteua beach (Pará, Brazil). Ocean \& Coastal Management, v. 46, p. 1.011-1.030, 2001.

QUINTAS, J. S.; GUALDA, M. J. A formação do educador para atuar no processo de gestão ambiental. Brasília: Ibama, 1995.

REIGOTA, M. Desafios à educação ambiental escolar. In: JACOBI, P. et al. (Org.). Educação, meio ambiente e cidadania: reflexões e experiências. São Paulo: SMA, 1998. p. 43-50.

RICHARDSON, R. J. Pesquisa social: métodos e técnicas. 3. ed. São Paulo: Atlas, 1999. SAUVÉ, L. Pour une éducation relative à l'environnement. 2. ed. Montréal: Guérin, 1997.

Recebido em: 31/1/2016

Aceito em: 2/8/2016 